\title{
The Effect of Eating Even or Odd Number of Dates, on Blood Glucose Level
}

\author{
Maha A. Al-Nuaimi' ${ }^{1}$, Yossra K. Al-Robaiaay1, Tawfeeq F. R. AL-Auqbi2* \\ ${ }^{1}$ College of Medicine / Al-Mustansiriyah University. Al-Yarmook Teaching Hospital Campus, \\ Baghdad, IRAQ \\ ${ }^{2}$ National Diabetes Centre / Al-Mustansiriyah University. Al-Yarmook Teaching Hospital \\ Campus, Baghdad, IRAQ \\ *Corresponding Author E-mail: tawfeeqauqbi@yahoo.co.uk
}

Received: 10 October 2018, Revised: 11 March 2019, Accepted: 15 March 2019

\begin{abstract}
Objectives: There is a common belief among Muslims, to consume dates in odd number rather than even, based on cultural and religious claims; although nobody knows its effect on blood glucose level or other metabolic effects in the body.

The aim of our study is to illuminate the changes that affect the 2-hrs postprandial serum glucose level after the consumption of an odd number of dates among healthy young persons and even number.

Method: Intervention study was used to compare 2 groups, Fasting glucose levels was measured for all participants; group A (42 participants), who consumed even number of dates all at Tamer-stage, (net weight about 50 grams); and group B, (42 participants), presumed to consume an odd number of dates (net weight about 40 grams). Two hrs postprandial blood glucose levels were measured altogether. Blood glucose levels were determined and compared as a means. Statistical analyses were performed using SPSS version 22.
\end{abstract}

Result: The fasting serum glucose of group A and B participants were $91.65 \pm 13.61$ and $93.69 \pm 8.79 \mathrm{mg} / \mathrm{dl}$, respectively, with an insignificant statistical difference between groups $(\mathrm{P}=0.42327)$. Subsequently, the $2 \mathrm{hrs}$ Postprandial Glucose measurements of group A and B were $99.58 \pm 19.56$ and $100.33 \pm 12.204$ respectively; indicated an insignificant statistical difference between groups, $(\mathrm{P}=0.83553)$. All the participants were remaining within normal ranges of serum glucose level.

Conclusion: There is no difference between ingestion of the odd and even number of dates fleshes from the glycemic point of view on the glucose level in fasting and postprandial states.

Key words: Eating dates, Odd, Even, Glucose level.

\section{Introduction}

There is a common belief among Muslims, to consume dates in odd number rather than even, based on cultural and religious claims. The changes that affect the 2-hrs postprandial serum glucose level after the consumption of odd or even numbers of dates among healthy 
young persons were studied; and showed no difference between ingestion of the odd and even number of dates fleshes from the metabolic point of view on the glucose level in fasting and postprandial states.

\section{Background}

The date is one of the ancient plants, eldest diet with high energy producing value; it is widely cultivated and adopted in various tropical and subtropical countries worldwide (Tengberg, 2012).

Each date flesh consists of about $60-65 \%$ carbohydrates, $2.5 \%$ fiber, $2 \%$ protein, $>2 \%$ fat, minerals, and about 15-30\% water according to the stage of ripeness and the variety of dates. Additionally, date can provide more than 3000 Calories/kg (Al-Shahib et al., 2003), that's mean the consumption of $100 \mathrm{~g}$ dates daily (six to seven dates) can provide the human body with a wide variety of vitamins, salts, minerals and provided $50 \%-100 \%$ of the recommended daily intake of fiber (Al-Shahib et al., 2002). These facts make dates as a most nourishing natural food and best food for consumption by all ages of the population all over the world (Al-Shahib et al., 2003, Zaid et al.).

Even though, some researches, found that the glycemic index (GI) of dates is low and its consumption does not cause a significant shot in the post-prandial blood glucose level, with glycemic indices (GIs) range (35.5-47.2) putting the dates in the list of the low GI food items (Miller et al., 2002, Alkaabi et al., 2011). Deserve to be one of the fruits which are widely consumed worldwide, particularly in the Arab and Islamic regions and it is one of the few numbers of foods that are directly mentioned in the Holly Qur'an (Touzani et al., 2008).

However, there is a common belief among Muslims, most of them, they advised to consume dates in odd number rather than even (Mahmoodi et al., 2012), although, nobody knows the effect of date number on blood glucose level or other metabolic effects in the body, as well as there was no previous scientific research spot the light on this subject. For these reasons, we try in this study to determine effect of the date number on blood glucose levels.

The aim of our study is to illuminate the changes that affect the 2-hrs. Postprandial Serum Glucose (2hs.PPSG) level after the consumption of odd and even numbers of deaths among healthy younger persons with normal Fasting Serum Glucose (FSG) level and their related variables.

\section{Materials and Methods}

\section{Study design}

Intervention study was used to compare the glucose levels before and after ingestion of odd and even pattern of dates among two matched study groups.

\section{Sample recruitments}

Participants were recruited from the College members, employees and students of the Chemical Engineering Department/College of Engineering/Baghdad University, who were informed to participate through invitation posters. The data collection extended from the 1st November to the 1st December 2017. 


\section{Flow chart of the study}

An 84 participants were completely eligible (42males and 42 females) fit for the inclusion criterion and were recruited for simple randomization to divide them into two groups (no blinding was used); group A (42 participants, 21 male and 21 female), who would consume even number of dates (net weight about 50 grams); and group B, (42 participants, 21 male and 21 female), presumed to consume an odd number of dates (net weight about 40 grams) (Figure 1).

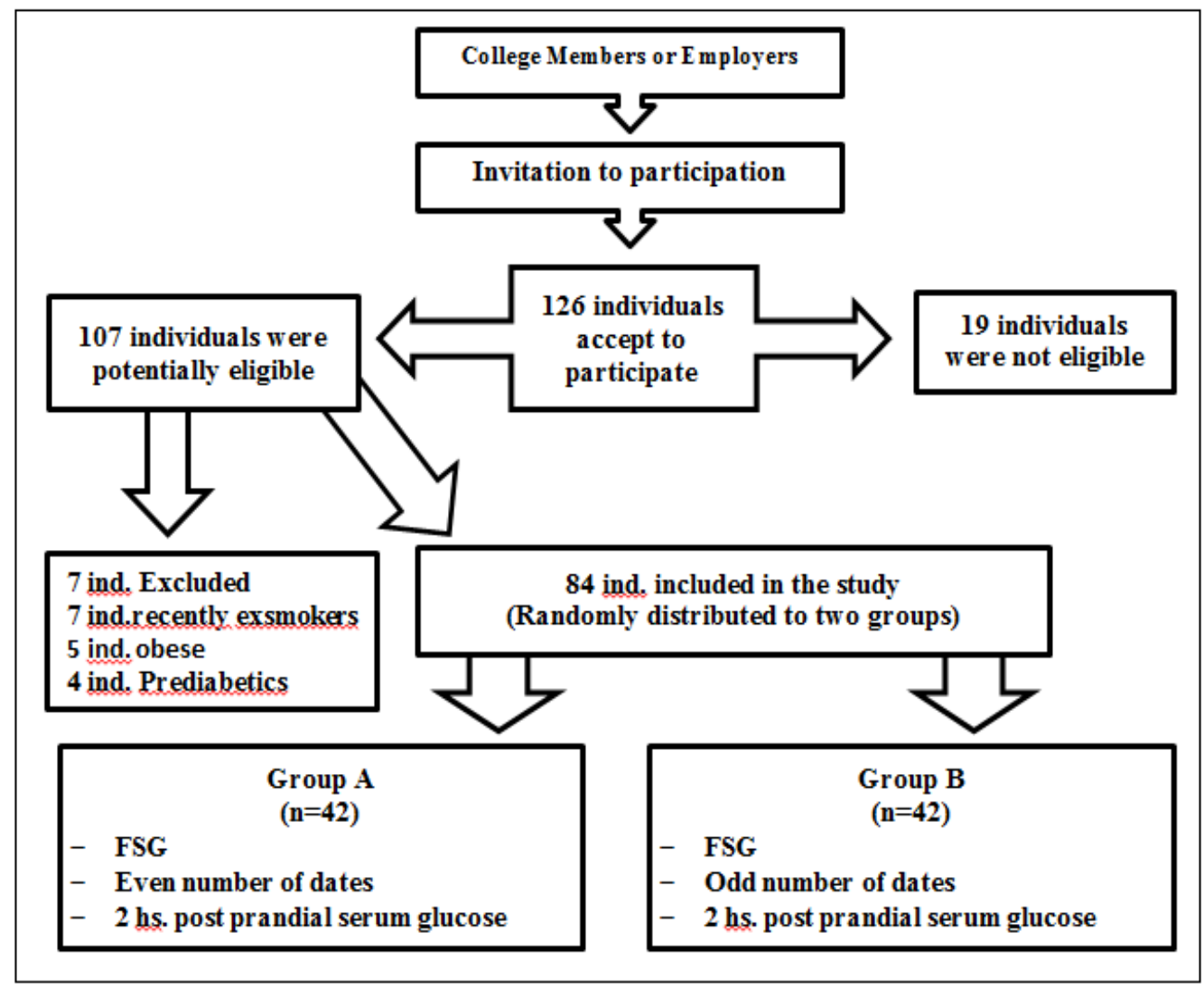

Figure 1. Flowchart of study

\section{Study protocol}

All the participants were asked to have overnight fasting and to stay fasting until they attend to the college at 7.30-8.30 AM. A sample of blood was taken from each one for measurement of FSG level, and then everyone asked to eat 4 or 5 fleshes of dates according to their groups. All flesh of dates was of the same type, at Tamer-stage, each flesh had an average weight of 9.25-10.10 grams. Participants ingest the dates followed by a glass of water $(100 \mathrm{~mL})$ and to stay on this regimen without additional foods or drinks, till the $2 \mathrm{hs} . P P S G$ levels were measured. Upon the end of the trial, the subjects would become free to join their daily activity.

Samples of blood were collected from all participants to be examined later, in the National Diabetes Center (NDC)/Al-Mustansiriyah University laboratory, for the investigation of FSG and 2hs.PPSG levels; KENZA 240TX auto analyzer was used for this purpose. 
The inclusion criteria; were non-smokers, healthy persons (no diabetes, no chronic disease, nor other co-morbidities even the metabolic problems), males and females of age ranging between $18-50$ years.

The exclusion criteria; were the obesity and morbid obesity (BMI $>35 \mathrm{~kg} / \mathrm{m} 2$ ) or a history of previous obesity, pre-diabetes (fasting blood sugar $\geq 100 \mathrm{gm} / \mathrm{dl}$ ) (9), alcoholic persons, pregnant women.

\section{Ethical approval}

Consents for participation in the study were obtained according to the Helsinki II Declaration (10), after a briefing about the project; and approved by the ethics committee and the scientific research committee at the National Diabetes Center and the College of Medicine/Al-Mustansiriyah University. The demographic data, family and past medical history of participants were recorded also; physical examination of pulse rate, blood pressure and anthropometric measurements of weight, height as well as BMI was measured for all participants.

\section{Statistical analysis}

All obtained data and records were managed by SPSS, version: 22, for statistical analysis. The Anderson-Darling test was done to prove normal distribution of the obtained data, student t-test was used for the comparison of two means, and chi square test was used to compare non numerical discrete data.

\section{Results and Discussion}

Age, gender distribution of group $\mathrm{A}$ and $\mathrm{B}$ and their BMI values, revealed insignificant statistical differences $(\mathrm{P}=0.48771,0.01792,0.801$ respectively). This mostly due to the cautious manner of choosing samples, and randomization in group recruitment rendered them equivalent and comparable (Table 1).

Family history of diabetes mellitus among study participants showed statistical significant difference between groups $(\mathrm{P}=0.00072)$. This expected figure may be because diabetes is a common disorder in Iraq and all over the world $(11,12)$ (Table 1).

Table 1. Characteristics of study groups participants

\begin{tabular}{|c|c|c|c|c|c|}
\hline & & $\begin{array}{c}\text { Group A } \\
\text { (EVEN) } n=41 \\
\end{array}$ & $\begin{array}{c}\text { Group B (ODD) } \\
n=42\end{array}$ & $\begin{array}{l}\text { Sig. (P } \\
\text { value) }\end{array}$ & Notes \\
\hline \multicolumn{2}{|l|}{ Age } & $30.41 \pm 11.68$ & $28.64 \pm 11.46$ & 0.4877 & $\begin{array}{c}\text { Student t-test, not } \\
\text { significant }(\mathrm{P} \geq \\
0.05)\end{array}$ \\
\hline \multicolumn{2}{|l|}{ BMI } & $24.22 \pm 4.79$ & $24.51 \pm 5.54$ & 0.801 & \\
\hline \multirow[t]{2}{*}{ Gender } & Male & 21 & 21 & 0.0179 & $\begin{array}{c}\text { Chi square test, not } \\
\text { significant }(\mathrm{P} \geq \\
0.05)\end{array}$ \\
\hline & Female & 21 & 21 & & \\
\hline \multirow[t]{2}{*}{$\begin{array}{l}\text { Family history of } \\
\text { diabetes mellitus }\end{array}$} & Yes & 9 & 20 & 0.0007 & $\begin{array}{c}\text { Chi square test, } \\
\text { Significant }(P \leq \\
0.005)\end{array}$ \\
\hline & No & 32 & 22 & & \\
\hline
\end{tabular}


The mean of Measurements of the Fasting Serum Glucose (FSG) of group A and B participants' were $91.65 \pm 13.61$ and $93.69 \pm 8.79 \mathrm{mg} / \mathrm{dl}$, respectively, with insignificant statistical difference between groups $(\mathrm{P}=0.42327)$; indicates no any pre diabetic was detected among the participants according to the diagnostic criteria (13). This healthy metabolic state of respondents, often owing to the high commitment to the study protocol during sample selection (Table 2).

Participants ingested the dates in an odd or even number of fleshes according to their groups. Dates ingested contain about the same amount of glucose used in oral glucose tolerance test, which is a more definitive test that have no serious risks and give important clues about health; in addition an Oral Glucose Tolerance Test (OGTT) shows how well your body handles sugar from foods $(14,15,16)$. Subsequently, after ingestion of dates, the means of 2 hours PPSG measurements of group A and B were $99.58 \pm 19.56$ and $100.33 \pm 12.20$ respectively, with insignificant statistical difference between groups, $(\mathrm{P}=0.83553)$, the higher figure of PPSG found in group $\mathrm{B}$ (odd group) may be attributed to the (extra one date) given to this group that might cause trifling personal differences. However, these changes did not manifest itself statistically. Moreover, the Changes of the glucose level for each participant among group $A$ and $B$ before and after ingestion of the dates seem to be insignificantly different $(\mathrm{P}=0.62089)$. Furthermore, all the participants were remaining within normal ranges of serum glucose levels, despite $34.5 \%$ of them were found to be with positive family history but they showed no glycemic response to date ingestion. This may be because the vast majority of this sample was young and below the risk of development, such health problem (17).

Obviously this indicates the negligible and a trivial effect of ingestion of dates in odd or even manner on the glucose metabolic state with no statistical meaning (Table 2).

Table 2. Characteristics of study groups participants, according to blood glucose measurement

\begin{tabular}{ccccc}
\hline & $\begin{array}{c}\text { Group A } \\
\text { (EVEN) } \mathbf{n = 4 2}\end{array}$ & $\begin{array}{c}\text { Group B } \\
\text { (ODD) } \mathbf{n = 4 2}\end{array}$ & $\begin{array}{c}\text { Sig. (P } \\
\text { value) }\end{array}$ & Notes \\
\hline FSG & $91.65 \pm 13.61$ & $93.69 \pm 8.79$ & 0.4232 & $\begin{array}{c}\text { Student t-test, not } \\
\text { significant }(\mathrm{P} \geq 0.05)\end{array}$ \\
& & & & \\
2 hs. PPSG & $99.58 \pm 19.56$ & $100.33 \pm 12.20$ & 0.8355 & \\
Change of glu. level & $9.95 \pm 21.19$ & $7.97 \pm 14.49$ & 0.6208 & \\
\hline
\end{tabular}

Although there is no obvious indication to ingest dates in any manner in Islamic references, but still there is habitual concept designed or formatted on religious bases solidified through multiple eras to become virtually a traditional norm. Because it ignores the size, weight, dryness and serving form of the dates which seriously affect its chemical components specially the carbohydrate, the glycemic index and glycemic load of any ingested food.

\section{Conclusion}

There is no difference between ingestion of odd or even number of date fleshes from the glycemic point of view on the glucose level in fasting and postprandial states. 


\section{Acknowledgements}

All thanks and appreciation for the staff of biochemistry Lab., National Diabetes Centre / AlMustansiriyah University; for their generous efforts and participation in this study.

\section{References}

Alkaabi, MJ, Al-Dabbagh, B, Ahmad, Sh, Saadi, FH, Gariballa, S, and Al Ghazali, M. (2011). Glycemic indices of five varieties of dates in healthy and diabetic subjects. Nutr J, 10:59.

Al-Shahib, W, Marshall, RJ. (2003). "The fruit of the date palm: its possible use as the best food for the future?", Int J Food Sci Nutr, 54 (4):247-259.

Al-Shahib, W, Marshall, RJ. (2002). Dietary fibre content of dates from 13 varieties of date palm Phoenix dactylifera L., Int J Food Sci Technol, 37:719-721. Doi:10.1046/j.1365-

Mahmoodi, SA, and Shamsi, M. (2012). Life-Style from the Perspective of Islam and Modern Medicine, World J Med Sci, 12 (4): 341-348.

Miller CJ, Dunn EV, Hashim IB. (2002), Glycemic index of 3 varieties of dates. Saudi Med J, 23(5):536-538

Tengberg, M. (2012). "Beginnings and early history of date palm garden cultivation in the Middle East". J Arid Environ, 86:139-147.

Zaid A, De Wet PF. Origin, geographical distribution and nutritional values of date PALM. Date palm cultivation. Date Production Support Programme, FAO Corporation Document Repository. Agriculture and Consumer Protection.

Touzani, M, Elizabeth Hirschman, C. (2008). "Cultural Syncretism and Ramadan Observance: Consumer Research Visits Islam", in NA - Advances in Consumer Research Volume 35, eds. Angela Y. Lee and Dilip Soman, Duluth, MN: Association for Consumer Research, Pages: 374-380.

American Diabetes Association. Diabetes Care. 2014:37 Suppl. 1: S81-90.

World Health Organization (2001). Declaration of Helsinki, World Medical Association Declaration of Helsinki, Ethical Principles for Medical Research Involving Human Subjects. $\begin{array}{lllll}\text { Bull World } & \text { Health } & \text { Organ, } & 79 & \text { (4):373 }\end{array}$ http://www.who.int/bulletin/archives/79\%284\%29373.pdf

MOH-Iraq/WHO. National guidelines for health care physicians: Diabetes management. 2008.

MOH-Iraq/USAID. Primary Health Care Project. Guideline for Diabetes Mellitus and Metabolic Syndrome Management. Iraq $\quad$ April 2012. http://lms.phciraq.org/sites/default/files/ncd_diabetes_and_metabolic_syndrome_english. pdf 
American Diabetes Association. (2016). Standards of medical care in diabetes-2016. Diabetes Screening and Diagnosis, Diabetes Care. 39(suppl. 1): S1-S106.

Tricia Kinman, Peggy Pletcher. Glucose Tolerance Test, on August 9, 2016. https://www.healthline.com/health/glucose-tolerance-test\#followup

Glucose screening and glucose tolerance tests. https://www.babycenter.com/0_glucosescreening-and-glucose-tolerance-tests_1483.bc

https://www.webmd.com/diabetes/guide/oral-glucose-tolerance-test\#1

International Diabetes Federation (IDF). IDF MENA. https://www.idf.org/ournetwork/regions-members/middle-east-and-north-africa/members/36-iraq.html

How to cite this article: Maha A. Al-Nuaimi, Yossra K. Al-Robaiaay, Tawfeeq F. R. ALAuqbi, The Effect of Eating Even or Odd Number of Dates, on Blood Glucose Level. International Journal of Advanced Biological and Biomedical Research, 2019, 7(2), 184-190. Link: http://www.ijabbr.com/article 34661.html 